\title{
A relação entre as crenças verbalizadas e depreendidas das ações do professor de Língua Inglesa no que tange ao ensino mediado pelas novas tecnologias
}

\section{The relation between what is said and what is done by the English Teacher when it comes to language teaching mediated by new technologies}

\begin{abstract}
Kássia Gonçalves Arantes*
Resumo: O objetivo deste trabalho é investigar a relação entre o dizer e o fazer do professor, no que tange à influência das novas tecnologias no ensino e aprendizagem de língua inglesa, bem como identificar os fatores que se articulam para o estabelecimento dessa relação. Para tanto, fazemos o confronto entre as crenças manifestadas no dizer do professor e as crenças depreendidas de seu fazer. Inserida numa perspectiva predominantemente qualitativa de cunho interpretativista, a pesquisa adota uma abordagem contextual de investigação de crenças de professores. O trabalho é fundamentado teoricamente em estudos que abordam as crenças de professores, o papel das novas tecnologias nos processos de ensino e aprendizagem de língua estrangeira, e a relação entre o professor reflexivo e a utilização das novas tecnologias. Os principais resultados encontrados apontam predominantemente para uma relação de dissonância entre o dizer e o fazer dos professores, e os fatores articuladores dessa relação se enquadram em quatro classes, a saber: fatores contextuais, experienciais, cognitivos e afetivos.
\end{abstract}

Palavras-chave: ensino de línguas; crenças; novas tecnologias.

Abstract: This study aims at investigating the interrelation between what teachers say and do, as for the influence of new technologies on English language teaching and learning, as well as identifying the factors which combine for the establishment of this interrelation. For this purpose, we confront the verbalizations of the teacher's beliefs and the beliefs inferred from their actions. Grounded on a qualitative-interpretive perspective, the research adopts a contextual approach to the investigation of teachers' beliefs. Our theoretical framework includes studies about teachers' beliefs, the role of technologies on English language teaching and learning processes, and the interrelation between the reflective teacher and the use of new technologies. The main outcomes point fundamentally to a relationship of dissonance between what the teachers say and do, and the articulating factors for this interrelation are encompassed in the four following classes: contextual, experiential, cognitive and affective factors.

Keywords: Language teaching; teachers' beliefs; new technologies.

\section{Introdução}

O presente artigo consiste em um recorte de minha dissertação de Mestrado intitulada "O ensino de Língua Inglesa e as novas tecnologias: a relação entre o dizer e o fazer do professor."

\footnotetext{
* Professora de Língua Inglesa da Escola de Educação Básica da Universidade Federal de Uberlândia. Mestre em Linguística pela mesma instituição.
} 
Já há algum tempo se tem discutido acerca do ensino mediado por novas tecnologias nas diversas áreas do conhecimento e tal modalidade de ensino oferece hoje recursos outrora inimagináveis.

$\mathrm{O}$ ensino de língua estrangeira (doravante LE) tem particularmente se beneficiado desse desenvolvimento, pois este tem possibilitado uma gama quase inesgotável de aplicações das tecnologias, e mais notadamente, do computador. Sua utilização vai desde uma simples ferramenta que permite ao aluno praticar exercícios com um feedback imediato até à real interação com falantes da língua-alvo através de recursos oferecidos pela Internet.

Warschauer (1996) afirma que os professores de línguas deveriam refletir sobre as implicações dos computadores na aprendizagem de línguas, visto a dramática expansão das aplicações dos mesmos observada atualmente.

A nosso ver, essa constatação de Warschauer (1996) a respeito das implicações dos computadores na aprendizagem de línguas pode ser estendida a outras tecnologias como retroprojetores, câmeras fotográficas, filmadoras, aparelhos de videocassete, $\mathrm{CD}$ players, aparelhos de DVD, MP3 players, Ipods, Ipads e smartphones. Algumas dessas tecnologias já são utilizadas há um certo tempo e outras vêm despontando recentemente como possíveis recursos nas salas de aula de LE. Acreditamos que a não familiarização com essas tecnologias possa privar o professor de ferramentas com potencial para enriquecer de forma considerável os processos de ensino e aprendizagem de línguas, e daí a relevância de se refletir sobre a utilização das mesmas.

Esclarecemos, portanto, que no escopo deste trabalho, ao nos referirmos às novas tecnologias, cuja definição abordaremos mais adiante, não nos referimos somente a computadores, mas a ferramentas diversas que de uma forma ou de outra interferem nos processos de ensino e aprendizagem de LE.

Na nossa concepção, um bom professor de LE é aquele capaz de refletir criticamente sobre sua prática e reavaliá-la constantemente. Conforme asseveram autores como Freire (2003) e Almeida Filho (2005a), um profissional crítico da educação deve ser capaz de articular o diálogo entre o fazer e o pensar sobre o fazer.

Esse processo reflexivo, ou seja, esse "pensar sobre o fazer" deveria abranger aspectos múltiplos da prática do professor, e por essa razão, nos remetemos uma vez mais a Warschauer (1996), e reafirmamos sua sugestão para que o professor de línguas 
reflita também sobre as implicações das novas tecnologias nos processos de ensino e aprendizagem de LE.

Ao abordarmos a prática do professor, consideramos que esse "fazer" é influenciado, dentre outros fatores, pelas crenças que o professor traz consigo e que são construídas ao longo de toda sua vida enquanto aprendiz e/ou educador. De acordo com Barcelos, Batista e Andrade (2004, p. 14), "a importância das crenças está relacionada à influência que elas podem exercer na prática pedagógica dos professores”.

Faz-se necessário compreender melhor a relação entre crenças, ações e o contexto. Logo, "é preciso investigar como acontece essa relação complexa entre crenças e ações" (BARCELOS, 2006, p. 35) e qual a influência do contexto na mesma.

Diante do exposto, propomo-nos a investigar a relação entre o dizer e o fazer do professor no que tange à influência das novas tecnologias no ensino de língua inglesa (doravante LI), levando em consideração o contexto no qual o professor se encontra inserido.

Ressaltamos que ao nos referirmos ao dizer do professor, estamos tratando da manifestação verbal de suas crenças e ao mencionarmos o seu fazer, nos referimos às crenças depreendidas de suas ações.

Em se tratando de um aspecto do processo educacional tão debatido, e ainda assim, tão controverso na atualidade, acreditamos que as novas tecnologias promovam uma relação multifacetada entre as crenças manifestadas verbalmente e as crenças depreendidas das ações do professor. Ademais, partimos do pressuposto de que vários são os fatores que subjazem ao estabelecimento dessa relação.

O nosso principal objetivo por meio deste trabalho se configura, portanto, investigar a relação entre o dizer e o fazer do professor com relação à influência das novas tecnologias no ensino e aprendizagem de LI, buscando a articulação dos fatores que interferem nessa relação.

Para atingirmos o objetivo geral acima proposto, desdobramos o mesmo nos seguintes objetivos específicos:

- Identificar as crenças que permeiam a instituição investigada sobre a influência das novas tecnologias no ensino e aprendizagem de LI;

- Identificar as crenças manifestadas no dizer do professor sobre a influência das novas tecnologias no ensino e aprendizagem de LI; 
- Depreender as crenças implícitas no fazer do professor sobre a influência das novas tecnologias no ensino e aprendizagem de LI;

- Identificar a natureza da relação entre o dizer e o fazer do professor no que concerne à influência das novas tecnologias no ensino e aprendizagem de LI;

- Investigar os fatores que se articulam na construção da relação entre o dizer e o fazer do professor.

De acordo com nossa proposta, optamos por realizar um estudo de caso, visto que o nosso objetivo consiste em focalizar uma situação específica dentro de um contexto específico, e não em promover generalizações. Por se tratar de um estudo de crenças de professores de línguas, nos embasamos em Barcelos (2001) para a definição da abordagem que norteia a nossa pesquisa.

\section{Referencial teórico}

Tendo em vista o nosso propósito de investigar a relação entre o dizer e o fazer do professor com relação à influência das novas tecnologias no ensino e aprendizagem de LI, nos respaldamos primordialmente em estudos sobre: (i) o papel das novas tecnologias no ensino de LE, levando em consideração tanto seu aspecto histórico quanto social, (ii) as crenças do professor de LE e a relação destas com a prática do professor.

\section{As novas tecnologias}

No mundo globalizado em que vivemos, tendo em vista o alcance dos avanços tecnológicos nos múltiplos setores da sociedade, uma demanda que percebemos no contexto de ensino e aprendizagem de LE se refere à expectativa de utilização das chamadas novas tecnologias.

Muito se discute a respeito da influência das novas tecnologias na educação e sobre a crescente variedade de aparatos tecnológicos com potencial de aplicação nos processos de ensino e aprendizagem. Mas, afinal , o que são novas tecnologias?

Em sua acepção original, tecnologia se configura a "teoria geral e/ou estudo sistemático sobre técnicas, processos, métodos, meios e instrumentos de um ou mais ofícios ou domínios da atividade humana.” (HOUAISS, 2001). Por extensão de sentido, Houaiss apresenta ainda outro verbete que define tecnologia como "qualquer técnica moderna e complexa”. Esse último verbete está mais de acordo com a acepção de 
tecnologia usualmente aceita pela sociedade moderna, exceto pelo fato, talvez, de se tratar da técnica especificamente e não do instrumento em si, como normalmente o faz o senso comum.

Por outro lado, ao nos depararmos com essa definição, constatamos a natureza pleonástica da locução novas tecnologias, utilizada por nós e por praticamente toda a literatura que aborda a relação entre essas e a educação. A partir do momento que tecnologia significa técnica moderna, a imprescindibilidade do termo 'novas' passa a ser questionada.

Houaiss (2001) nos traz ainda a locução alta tecnologia ou tecnologia de ponta, a qual é definida como "técnica avançada, de última geração". À primeira vista essa locução pode aparentar um caráter também redundante, mas que nos parece mais apropriado que o amplamente difundido 'novas tecnologias'. Afinal, com base em que parâmetros se estabelece o que é novo e o que não é?

O novo nos parece algo subjetivo, que depende muito da perspectiva de quem utiliza o termo. Para Almeida (2007, s/p), o "novo não é uma propriedade da matéria, mas uma qualidade da consciência." Para o autor, o novo não reside em um lugar específico, mas habita as consciências que se mostram receptivas. Ou seja, a novidade não se encontra na técnica ou na ferramenta, mas na abordagem de quem as observa ou utiliza.

Diante disso, nos questionamos qual seria a nossa concepção de novas tecnologias, considerando que, por uma questão de adequação ao campo de pesquisa no qual nos encontramos inseridos, optamos pela utilização desse termo, ainda que conceitualmente redundante.

Combase no contexto e nos propósitos de nossa investigação, adotamos a noção de novas tecnologias com base na concepção de novo proposta por Almeida (2007), visto que na nossa abordagem não nos interessa o grau de modernidade ou novidade subjacente a determinadas técnicas ou ferramentas, mas sim o olhar do usuário sobre as mesmas.

Assim sendo, definimos novas tecnologias no escopo desse trabalho como técnicas e/ou ferramentas que visam a otimizar processos já existentes e/ou propiciar a realização de novos. 


\section{As novas tecnologias e o ensino de LE}

Em sua excelente retrospectiva sobre o uso da tecnologia para o ensino e aprendizagem de segunda língua, Salaberry (2001, p. 52) argumenta que, "enquanto a maioria das 'novas tecnologias' (rádio, televisão, videocassete, computadores) podem ter sido revolucionárias no contexto geral da interação humana, não está claro se elas alcançaram níveis semelhantes de benefício pedagógico no domínio do ensino de segunda língua". Ou seja, o autor questiona a efetiva contribuição das chamadas novas tecnologias para o desenvolvimento da área de ensino de línguas e o aperfeiçoamento dos processos de ensino e aprendizagem de LE.

Contudo, ainda que haja divergências acerca da real contribuição das chamadas novas tecnologias para o desenvolvimento do ensino e aprendizagem de LE, é inegável que de uma forma ou de outra, esses processos sejam afetados por elas.

Leffa (2002) faz uma consideração pertinente ao abordar a questão da realfabetização que se coloca como um desafio aos professores na atualidade. Ele pondera que o professor da época da introdução da imprensa talvez preferisse os livros caprichosamente copiados pelos escribas, mas que ele precisou se realfabetizar. Analogamente, o professor do terceiro milênio pode preferir formas mais tradicionais de se redigir um texto, como escrevê-lo e apagá-lo várias vezes usando lápis e borracha, mas ele não pode ignorar que tecnologias mais modernas já estão disponíveis para o empreendimento de tal ação.

Conforme sugerem Sampaio e Leite (1999), o professor precisa se conscientizar de que vivemos num mundo hoje onde distintos meios podem levar ao raciocínio e ao conhecimento e que a aula expositiva não se constitui mais a única forma pela qual se dá a aprendizagem. As autoras postulam que, "assim como qualquer instrumento, as tecnologias que servem para comunicar e produzir podem se adequar a variados objetivos preestabelecidos pelo sistema educacional ou pela escola. Por isso, faz-se necessária a reflexão sobre seu papel no ambiente escolar.” (SAMPAIO; LEITE, 1999, p. 20).

Há muito se iniciou o relacionamento entre o ensino de LE e as novas tecnologias e este tem se estreitado cada vez mais. Da mesma maneira que a tecnologia se aperfeiçoa e com isso amplia-se sua gama de aplicações, as pesquisas na área de ensino e aprendizagem de línguas têm constantemente buscado novas formas de se utilizar as tecnologias em consonância com as abordagens de ensino adotadas. 
Conforme afirmam Sampaio e Leite (1999), as tecnologias, assim como o mundo em geral, estão em constante transformação e devem ser interpretadas crítica e permanentemente. À medida que surgem novos avanços tecnológicos e se aprimora a pesquisa na área do ensino de línguas, mais frutífera se torna essa parceria.

\section{O professor reflexivo e as novas tecnologias}

O papel do professor de línguas estrangeiras tem crescido à proporção do crescimento da globalização mundial. Segundo Leffa (2002, p. 104), "na medida em que aumentam as relações entre as pessoas, mediadas basicamente pela linguagem, aumenta a importância do professor de línguas estrangeiras, que pode estar vivendo, agora, seu melhor momento histórico".

A ampliação da importância do seu papel não deve ser tomada pelo professor apenas como uma responsabilidade a mais a ser agregada ao seu rol já tão extenso de atribuições, mas como uma grande oportunidade. Para assumir a importância do seu papel, o professor precisa evoluir, e para isso é essencial que ele desenvolva sua capacidade de rever sua prática por meio de um processo reflexivo.

São vastas as proporções assumidas pela discussão a respeito da formação crítico-reflexiva do professor nos últimos tempos, tanto no contexto do ensino e aprendizagem de línguas, como na educação em geral. Compartilhamos da opinião de Silva, Rocha e Sandei (2005, p. 24), ao afirmarem que "a questão da reflexão tem sido uma das tônicas centrais na área de formação de professores em contextos nacionais e internacionais." E acreditamos que esse processo não ocorre por acaso, e que não se trata de modismo ou de simples adesão ao discurso vigente.

Somente a partir de uma atitude reflexiva o professor pode se questionar e rever sua prática. A acomodação é um elemento perigoso nesse processo, pois o professor acomodado não questiona suas decisões pedagógicas, não abre espaço para a revisão de crenças e valores. Ao avaliar a sua prática a partir de uma perspectiva reflexiva, o professor pode detectar possíveis contradições entre o dizer e o fazer. E conforme postula Cavalcanti (1999, p. 181), “[...] essas contradições são iluminadoras,” pois, ao serem detectadas, possibilitam ao professor avaliar a necessidade de mudança.

Nesse processo de conscientização crítico-reflexiva do professor, faz-se necessário que a questão das novas tecnologias seja também levada em consideração, 
visto a importância destas para os processos de ensino e aprendizagem, conforme explicitado anteriormente.

Esse processo de familiarização com a aplicação das novas tecnologias no ensino é chamado de alfabetização tecnológica por Sampaio e Leite (1999). As autoras ressaltam que esse processo não pode se limitar ao seu aspecto mecânico de utilização dos recursos tecnológicos, mas deve abranger também o domínio crítico da tecnologia. E acrescentam que é preciso que professores "conheçam, interpretem, utilizem, reflitam e dominem criticamente a tecnologia para não serem por ela dominados" (SAMPAIO; LEITE, 1999, p. 19).

Assim como Sampaio e Leite (1999), Corrêa (2003), também defende aquilo que chama de visão crítica da tecnologia, com a construção de uma nova articulação entre tecnologia e educação. O professor é convocado a ir além e passar a/construir novos paradigmas, e não continuar reproduzindo os mesmos velhos padrões simplesmente utilizando-se agora de artefatos tecnológicos inovadores.

\section{As crenças do professor e o ensino de LE}

Acreditar em algo configura-se fator motivador da ação em qualquer domínio da existência humana. Agimos porque acreditamos que algo não está bom o suficiente e portanto, precisamos modificá-lo. Ou ao contrário, porque algo se apresenta exatamente como achamos que deveria, e por isso, não pode ser ameaçado em sua estabilidade. Em outras palavras, nossas crenças nos impelem a recuar, a agir ou a reagir, de acordo com a situação.

Barcelos (2001, p. 73) afirma que "uma das mais importantes características das crenças refere-se à sua influência no comportamento." Contudo, diversos pesquisadores que investigam a relação entre crenças e ações no contexto do ensino e aprendizagem de LE (GIMENEZ, 1994; RICHARDSON, 1996; MALATÉR, 1998; BORG, 2003; BARCELOS, 2000, 2001, 2004, 2006; VECHETINI, 2005) atestam a complexidade dessa relação.

Barcelos (2004), endossando outros pesquisadores, argumenta que nem sempre as crenças e as ações coincidem. Vechetini (2005, p. 138), por sua vez, afirma que ora há certas incongruências entre o discurso e a prática do professor, "ora há bastante coerência entre o seu dizer e o seu fazer". 
A autora sinaliza para a complexidade da relação entre crenças e ações, e acima de tudo, para a relação intrincada que estas estabelecem com o contexto do qual fazem parte. Compreende-se agora que crenças e ações não estabelecem uma relação lógica, mas que ao contrário, esse relacionamento é determinado por especificidades do contexto no qual é estabelecido.

Richardson (1996) acrescenta ainda que uma determinada crença do professor pode sustentar práticas distintas ou absolutamente prática nenhuma, caso ele não saiba como engendrar uma prática que corresponda àquela crença. Ou seja, não há uma relação determinística entre uma crença e sua prática subsequente, o que corrobora a natureza complexa e contextual dessa relação.

Malatér (1998) afirma que apesar de a influência exercida pelas crenças na prática do professor ser amplamente discutida na área, é inegável a existência de fatores que restringem essa influência. Dentre os vários fatores citados pela autora, destacamos a falta de recursos educacionais, pressões de tempo e avaliação, política da instituição e tensões no ambiente da sala de aula.

Em alguns casos, ainda que o professor tenha uma crença e manifeste a intenção de agir de acordo com ela, outros fatores atuam de forma mais determinante na hora da concretização de sua prática.

Segundo Borg (1999), três classes de fatores atuam sobre as crenças do professor: fatores experienciais, fatores cognitivos e fatores contextuais. Os fatores experienciais referem-se a experiências educacionais e profissionais significativas que o professor tenha vivenciado, os fatores cognitivos estão relacionados a concepções e percepções trazidas pelo professor e os fatores contextuais referem-se a aspectos relacionados a contextos instrucionais específicos.

O que podemos inferir com base em pesquisas que investigam a relação entre crenças e ações é que esta se trata de uma relação complexa, interativa, contextual, e difícil de ser perscrutada, posto que inumeráveis fatores atuam tanto sobre as crenças como sobre as ações.

Diante dessa relação de imensa complexidade, ecoamos a pergunta que Barcelos (2006, p. 27) relata ser feita por vários pesquisadores iniciantes, dentre os quais nos enquadramos: mas "afinal, o que podemos considerar como crenças - o que os professores e alunos dizem ou o que fazem?" 
Barcelos (2001) sugere que as crenças não sejam inferidas somente por meio das verbalizações dos indivíduos, mas também através de suas intenções e ações. Analogamente, Basso (2006) argumenta que as crenças quase sempre são inferidas mais por meio do que as pessoas fazem do que pelo que dizem, dada a dificuldade de se medir as crenças.

Segundo Gimenez (1994), três são as perspectivas pelas quais as crenças são abordadas. A primeira posição sinaliza que as crenças são explícitas no nível da consciência, o que permite a materialização das mesmas em palavras. Ou seja, sob essa perspectiva, a verbalização das crenças se configura o foco de investigação das mesmas. $\mathrm{Na}$ segunda perspectiva, a linguagem cede lugar às interações observadas em sala de aula; isto é, argumenta-se que as crenças estão implícitas nas ações do professor e devem ser deduzidas por meio da observação do que ele faz em sala de aula. E na terceira, propõe-se uma combinação da análise das verbalizações e dos comportamentos como meio de investigação das crenças.

Com vistas a responder à pergunta de Barcelos (2006), e com o respaldo das autoras supracitadas, afirmamos que, na nossa concepção, consideramos como crenças tanto o que professores e alunos manifestam verbalmente, isto é, o seu dizer, como o que manifestam em suas ações, ou seja, o seu fazer. A nosso ver, as interpretações que o indivíduo faz da realidade se manifestam tanto em suas palavras como em suas ações.

Reafirmamos, assim, a nossa proposta de investigarmos a relação entre o dizer e o fazer do professor, por meio da investigação da relação entre as crenças manifestadas no dizer e as crenças manifestadas no fazer do professor no que tange à influência das novas tecnologias no ensino e aprendizagem de LI.

\section{Aspectos metodológicos}

Com respeito à abordagem metodológica utilizada em nosso trabalho para a investigação das crenças do professor, nos respaldamos em Barcelos (2001) e adotamos uma abordagem contextual, cuja perspectiva consiste em identificar e compreender as crenças de alunos (ou professores) em contextos específicos, e não generalizar sobre as crenças. Conforme aponta Vieira Abrahão (2006) nessa abordagem a relação entre crenças e ações não é simplesmente sugerida, mas investigada por intermédio da observação. 
A nossa pesquisa foi realizada em um instituto de idiomas de uma cidade de grande porte do interior de Minas Gerais e tivemos como participantes a pesquisadora, as coordenadoras pedagógicas e quatro professores de inglês do referido instituto.

Esses quatro professores foram selecionados a partir de um grupo inicial de participantes voluntários formado por 21 professores das quatro filiais do instituto, que responderam a um questionário semiaberto quando do início da coleta de dados. No processo de escolha dos mesmos procuramos selecionar professores que apresentassem características variadas com o intuito de aumentarmos as nossas possibilidades de identificação de diferentes fatores que influenciam o dizer e o fazer dos mesmos.

Para a nossa coleta de dados, nos valemos das seguintes fontes:

- questionário semiaberto para levantamento das crenças das coordenadoras pedagógicas do instituto a respeito da influência das novas tecnologias no ensino e aprendizagem de LI;

- material institucional composto pelo livro do professor (lesson plan) mais material de apoio pedagógico (livreto e apostila sobre o método de ensino adotado pela instituição);

- questionário semiaberto para levantamento das crenças do professor com relação à influência das novas tecnologias no ensino e aprendizagem de LI;

- notas de campo realizadas durante a observação de aulas dos quatro professores;

- entrevista realizada com os quatro professores cujas aulas foram observadas para confronto entre os dados coletados nos questionários e nas notas de campo quando da observação das aulas.

A entrevista e as notas de campo se configuram, a nosso ver, os instrumentos essenciais de nossa coleta, pois é a partir deles que podemos traçar a relação entre o dizer e o fazer do professor no que tange à aplicação das novas tecnologias no ensino e aprendizagem de LI, assim como estabelecer os fatores que influenciam essa relação.

O nosso objetivo a partir dos questionários semiabertos era coletar informações sobre o perfil dos professores do instituto e obter uma ideia geral sobre suas crenças, para que de posse dessas informações iniciais, pudéssemos selecionar os quatro professores os quais convidaríamos a participar de nossa pesquisa. 
Para a etapa subsequente da coleta de dados, agendamos as datas para as observações de aulas com os quatro professores participantes e escolhemos uma turma de nível básico, uma de nível intermediário e duas de nível avançado. Optamos por assistir a cinco aulas de cada professor, o que corresponde a seis horas e quinze minutos de aula por participante.

Cabe aqui prestar esclarecimentos sobre uma delicada questão ética que diz respeito a até que ponto os professores participantes, notadamente os quatro professores selecionados para participarem de toda a investigação, deveriam estar cientes do foco de nossa pesquisa. Optamos por informar a eles que o nosso trabalho se tratava de uma investigação a respeito da utilização de novas tecnologias, sem entrar em detalhes com relação à questão das crenças e a relação entre o dizer e o fazer do professor.

Nossa opção se justifica no risco de contaminação dos dados representado por essa informação, posto que a consciência desses professores sobre a nossa intenção de investigar a relação entre o dizer e o fazer do professor poderia levá-los a adotar comportamentos que eles julgassem se adequar aos parâmetros buscados por nós, conforme pontuado por Allwright e Bailey (1991). Optamos, desse modo, por fornecer informações mais gerais sobre os nossos objetivos aos professores, e nos comprometemos a informá-los sobre os detalhes de nossa pesquisa em um momento oportuno.

Terminado o processo de observação de aulas, e após uma primeira análise geral dos dados, elaboramos os roteiros e agendamos as entrevistas com os quatro professores participantes para confronto dos dados obtidos a partir dos dois primeiros instrumentos de pesquisa utilizados. As entrevistas foram gravadas em áudio e transcritas posteriormente para facilitar a análise dos dados.

\section{Análise e discussão dos dados}

A nossa análise de dados está organizada em quatro etapas, a saber: análise dos questionários, análise do material institucional composto pelo material didático e de apoio utilizados pelo professor e pela coordenação, análise das notas de campo provenientes da observação das aulas, e análise das entrevistas. Cabe ressaltar que essas quatro etapas não obedecem a uma ordem cronológica fixa e não estão desvinculadas 
umas das outras, havendo frequentemente o confronto entre os dados provenientes das mesmas.

Vale esclarecer que a análise das crenças nos questionários e entrevistas é feita a partir de trechos de fala (oral e escrita) que revelem as percepções dos participantes com respeito à influência das novas tecnologias nos processos de ensino e aprendizagem de LI. Por sua vez, as crenças implícitas no material institucional são depreendidas a partir das instruções relacionadas à utilização das novas tecnologias encontradas no livro do professor (lesson plan), e de quaisquer referências à tecnologia presentes no material de apoio pedagógico. Finalmente, as crenças depreendidas do fazer do professor são inferidas a partir de suas ações durante as aulas observadas.

Os excertos nos quais nos baseamos para depreendermos as crenças analisadas neste trabalho podem ser encontrados no trabalho completo do qual esse artigo foi originado, cujo título apresentamos em nossa introdução.

\section{Crenças institucionais}

Com o intento de identificarmos as crenças institucionais sobre a influência das novas tecnologias no ensino e aprendizagem de LI que permeiam o nosso contexto de pesquisa, nos valemos da análise dos questionários semiabertos respondidos pela coordenação da escola e da análise do material institucional composto pelo livro do professor (lesson plan) mais material de apoio pedagógico (livreto e apostila sobre o método de ensino adotado pela instituição).

Vale destacar, ainda, que o arrolamento das crenças é feito, na maioria das vezes, com base na recorrência dos temas aventados, mas devido à relevância de alguns temas mencionados de forma isolada, consideramos pertinente acrescentá-los ao rol das crenças.

\section{Da perspectiva da coordenação}

Partindo para a análise dos questionários semiabertos respondidos pela coordenação pedagógica da instituição, primeiramente classificamos os dados obtidos em crenças sobre a influência positiva das novas tecnologias no ensino e aprendizagem de LI e em crenças sobre a influência negativa das mesmas. Ou seja, separamos os 
aspectos positivos dos aspectos negativos mencionados. Vale esclarecer que essa se constitui a perspectiva escolhida por nós para abordarmos os dados coletados, em consonância com o instrumento de pesquisa adotado, no qual esses aspectos são destacados. Contudo, temos consciência de que esse se configura apenas um olhar sobre os dados, dentre os vários possíveis.

A partir dessa divisão em aspectos positivos e negativos, procuramos agrupar as crenças manifestadas pelos professores em categorias embasadas (BARCELOS, 2001), que foram surgindo no decurso de nossa análise.

\section{Da perspectiva do material institucional}

Ao analisarmos os três itens que compõem o material institucional, constatamos que nenhum traz qualquer justificativa para a adoção desta ou daquela tecnologia. Nenhuma menção é feita aos benefícios proporcionados pela utilização das chamadas novas tecnologias, ou seja, aparentemente, na perspectiva do material institucional, a adoção de recursos como um computador de última geração ou um aparelho de DVD não representa vantagem em comparação à utilização de um gravador e de um projetor de slides.

A tecnologia demonstra, portanto, atuar como um suporte ao método de ensino e às técnicas subjacentes a ele. Ela parece assumir o papel de materializadora dos princípios nos quais se baseiam o método de ensino adotado pela instituição, o que lhe confere uma posição central em todo o processo de ensino e aprendizagem no instituto de idiomas em questão.

Julgamos conveniente esclarecer que a crença depreendida do material institucional não necessariamente retrata a crença do(s) seu(s) autor(es). Essa se configura a nossa interpretação face às menções à tecnologia identificadas no material analisado.

As crenças institucionais identificadas estão representadas no quadro 1, a seguir: 
Revista Eletrônica de Linguística (http://www.seer.ufu.br/index.php/dominiosdelinguagem) Volume 6, - $\mathrm{n}^{\circ} 2-2^{\circ}$ Semestre 2012 - ISSN 1980-5799

Quadro 1: Crenças institucionais sobre a utilização das novas tecnologias no ensino e aprendizagem de LI

\begin{tabular}{|c|c|c|c|c|}
\hline \multirow{11}{*}{$\begin{array}{c}\text { Da perspectiva } \\
\text { da } \\
\text { coordenação }\end{array}$} & \multicolumn{2}{|r|}{ Aspectos positivos } & \multicolumn{2}{|r|}{ Aspectos negativos } \\
\hline & Categorias & \begin{tabular}{|c|} 
Crenças \\
\end{tabular} & Categorias & Crenças \\
\hline & \multirow{2}{*}{$\begin{array}{l}\text { Aspecto } \\
\text { utilitário }\end{array}$} & $\begin{array}{l}\text { As novas tecnologias se constituem instrumentos de } \\
\text { auxílio ao ensino, ao fornecerem subsídios } \\
\text { audiovisuais utilizados pelo professor em sala de aula. }\end{array}$ & Aspecto social & $\begin{array}{l}\text { As novas tecnologias podem acentuar o abismo social } \\
\text { no país. }\end{array}$ \\
\hline & & $\begin{array}{l}\text { As novas tecnologias são ferramentas utilizadas pelo } \\
\text { aluno como complemento à sua aprendizagem. }\end{array}$ & Papel do aluno & $\begin{array}{l}\text { As novas tecnologias podem levar } 0 \text { aluno à } \\
\text { acomodação. }\end{array}$ \\
\hline & Aula & As novas tecnologias tornam as aulas mais dinâmicas. & $\begin{array}{l}\text { Papel do } \\
\text { professor }\end{array}$ & $\begin{array}{l}\text { As novas tecnologias podem ser má empregadas pelo } \\
\text { professor de LI. }\end{array}$ \\
\hline & \multirow{2}{*}{ Cognição } & $\begin{array}{l}\text { As novas tecnologias influenciam } 0 \text { processo } \\
\text { cognitivo do aluno. }\end{array}$ & & \\
\hline & & $\begin{array}{l}\text { As novas tecnologias atuam como um fator } \\
\text { motivacional. }\end{array}$ & & \\
\hline & Flexibilidade & \begin{tabular}{|l|l|} 
As novas tecnologias flexibilizam o ensino de LI. \\
\end{tabular} & & $y$ \\
\hline & Informação & $\begin{array}{l}\text { As novas tecnologias viabilizam o acesso rápido à } \\
\text { informação de qualidade. }\end{array}$ & & \\
\hline & Interação & $\begin{array}{l}\text { A interação é facultada pela utilização das novas } \\
\text { tecnologias. }\end{array}$ & & \\
\hline & Tempo & As novas tecnologias otimizam a utilização do tempo. & & \\
\hline $\begin{array}{c}\text { Da perspectiva } \\
\text { do material }\end{array}$ & \multicolumn{4}{|c|}{ Crença implícita } \\
\hline
\end{tabular}

Essas crenças nos indicam as percepções e concepções que embasam o contexto no qual o professor investigado se inscreve, mais especificamente no que tange ao papel das novas tecnologias nos processos de ensino e aprendizagem de LI. A partir das visões da coordenação pedagógica e do material institucional, arrolamos as crenças institucionais sobre o tema em questão, as quais serão confrontadas posteriormente com as crenças do professor, de forma a identificarmos a possível influência das primeiras sobre as últimas.

\section{A relação entre o dizer e 0 fazer do professor}

Focalizamos agora o objetivo principal de nosso trabalho, que consiste em investigar a relação entre o dizer e o fazer do professor. Primeiramente, elencamos as crenças manifestadas no dizer do professor; em seguida, depreendemos as crenças implícitas em seu fazer e finalmente, confrontamos os dois grupos de crenças. A partir dessa contraposição, discutimos os fatores que se articulam no estabelecimento da referida relação.

Para o levantamento de tais fatores, nos valemos das crenças institucionais já discutidas, e dos dados analisados a seguir, que consistem das crenças do professor. Ademais, buscamos também outros indícios em excertos extraídos dos questionários e das entrevistas dos quatro professores participantes. 


\section{O dizer do professor}

Conforme mencionado anteriormente, ao nos referirmos ao dizer do professor, estamos tratando da manifestação verbal de suas crenças. No nosso caso, para identificarmos essas crenças, analisamos a manifestação das mesmas nos questionários semiabertos respondidos pelos quatro professores, quando da primeira etapa da coleta de dados, e nas entrevistas semiestruturadas, derradeira fase de nossa coleta.

Por se tratar de um número mais reduzido de crenças que o observado quando do levantamento das crenças institucionais, nesta etapa de nossa análise não julgamos haver a necessidade de categorização das mesmas. Ademais, outro ponto quemerece ser ressaltado é a ínfima menção desses quatro professores a aspectos negativos da utilização das novas tecnologias no ensino e aprendizagem de LI, o que nos levou a não abordar aspectos positivos e negativos como itens distintos. As raras ocorrências identificadas de crenças relacionadas a aspectos negativos são abordadas junto às demais crenças.

As crenças dos quatro professores participantes de nossa investigação podem ser resumidas no quadro 2, a seguir. Como forma de preservar o anonimato dos participantes, optamos por identificá-los por meio de pseudônimos escolhidos pelos próprios durante a entrevista final. 
Revista Eletrônica de Linguística (http://www.seer.ufu.br/index.php/dominiosdelinguagem) Volume $6,-\mathrm{n}^{\circ} 2-2^{\circ}$ Semestre 2012 - ISSN 1980-5799

Quadro 2: Crenças manifestadas no dizer do professor sobre a utilização das novas tecnologias no ensino e aprendizagem de LI

\begin{tabular}{|c|c|}
\hline Professor & Crenças manifestadas no dizer do professor \\
\hline \multirow{4}{*}{ João } & As novas tecnologias incrementam as aulas. \\
\hline & $\begin{array}{l}\text { As novas tecnologias são ferramentas utilizadas pelo aluno como } \\
\text { complemento à sua aprendizagem. }\end{array}$ \\
\hline & As novas tecnologias viabilizam o acesso à informação de qualidade. \\
\hline & As novas tecnologias podem causar dependência. \\
\hline \multirow{3}{*}{ Laura } & As novas tecnologias influenciam positivamente a aprendizagem de LI. \\
\hline & As novas tecnologias se restringem ao computador. \\
\hline & $\begin{array}{l}\text { O uso das novas tecnologias no ensino de LI pode tornar o processo um } \\
\text { pouco mecânico. }\end{array}$ \\
\hline \multirow{3}{*}{ Murilo } & As novas tecnologias atuam como um fator motivacional. \\
\hline & $\begin{array}{l}\text { As novas tecnologias se constituem instrumentos de auxílio ao ensino, ao } \\
\text { fornecerem subsídios audiovisuais utilizados pelo professor em sala de aula. }\end{array}$ \\
\hline & As novas tecnologias viabilizam o acesso à informação de qualidade. \\
\hline \multirow{3}{*}{ Paulo } & As novas tecnologias atuam como um fator motivacional. \\
\hline & $\begin{array}{l}\text { As novas tecnologias se constituem instrumentos de auxílio ao ensino, ao } \\
\text { fornecerem subsídios audiovisuais utilizados pelo professor em sala de aula. }\end{array}$ \\
\hline & causar dependência. \\
\hline
\end{tabular}

O quadro 2 nos permite identificar muitas crenças comuns entre os professores participantes. A excetuar pelas crenças da professora Laura, que não coincidem com as crenças de nenhum dos outros três professores, os demais compartilham a maioria de suas crenças, conforme ressaltamos durante a análise.

\section{O fazer do professor}

Para essa etapa de nossa análise, nos valemos das notas de campo registradas pela pesquisadora quando da observação das aulas dos quatro professores investigados. Conforme já mencionamos anteriormente, foram assistidas cinco aulas de cada um dos participantes, e durante a observação das mesmas, nos focamos nas ações dos professores relacionadas à utilização das novas tecnologias.

De forma análoga à análise das crenças realizada na subseção anterior, também abordamos as ações dos quatro professores separadamente de modo a facilitar a posterior comparação entre o dizer e o fazer dos mesmos.

A seguir, apresentamos um quadro com o resumo de tais ações dos quatro professores. 
Quadro 3: Utilização das novas tecnologias no ensino e aprendizagem de LI

\begin{tabular}{|c|l|}
\hline Professor & \multicolumn{1}{|c|}{ Utilização das novas tecnologias na aula de LI } \\
\hline \multirow{5}{*}{ João } & $\begin{array}{l}\text { A utilização das novas tecnologias praticamente se limita à TV e ao DVD player, com } \\
\text { exceção de uma atividade na primeira aula assistida na qual o computador é utilizado. }\end{array}$ \\
\cline { 2 - 3 } & $\begin{array}{l}\text { A natureza da utilização da TV e do DVD player segue os moldes prescritos pelo plano de } \\
\text { aula fornecido pela instituição. }\end{array}$ \\
\hline \multirow{3}{*}{ Laura } & A utilização das novas tecnologias se limita à TV e ao DVD player. \\
\cline { 2 - 3 } & $\begin{array}{l}\text { A natureza da utilização da TV e do DVD player segue os moldes prescritos pelo plano de } \\
\text { aula fornecido pela instituição. }\end{array}$ \\
\hline & $\begin{array}{l}\text { A utilização da TV e do DVD player também segue os moldes prescritos pelo plano de aula } \\
\text { fornecido pela instituição, porém não se limita a isso. }\end{array}$ \\
\cline { 2 - 3 } & $\begin{array}{l}\text { O professor utiliza seu notebook pessoal para incrementar as aulas de LI. } \\
\text { A Internet é acessada várias vezes durante as aulas para busca de informações que elucidem } \\
\text { e enriqueçam suas explicações. }\end{array}$ \\
\cline { 2 - 3 } & $\begin{array}{l}\text { Os recursos tecnológicos disponíveis são muito bem aproveitados para incrementar os } \\
\text { processos de ensino e aprendizagem nas aulas de LI }\end{array}$ \\
\hline \multirow{2}{*}{ Paulo } & A utilização das novas tecnologias se limita à TV e ao DVD player. \\
\cline { 2 - 3 } & $\begin{array}{l}\text { A natureza da utilização da TV e do DVD player segue os moldes prescritos pelo plano de } \\
\text { aula fornecido pela instituição. }\end{array}$ \\
\hline
\end{tabular}

\section{Crenças tácitas no fazer do professor}

Em consonância com os preceitos da abordagem contextual de investigação de crenças, além das crenças manifestadas verbalmente no dizer do professor, consideramos ainda as crenças que são 'ditas’ de forma indireta através de suas ações. São essas as crenças que chamamos de crenças tácitas, das quais tratamos nesta subseção.

A partir da observação das aulas e subsequente análise das notas de campo, representada no quadro 3 , depreendemos a seguinte crença comum aos quatro professores da instituição participantes da pesquisa:

- A utilização da tecnologia está condicionada às técnicas ditadas pelo método de ensino adotado.

Essa é uma crença inferida a partir das ações dos quatro professores em todas as aulas observadas, considerando que nas cinco aulas todos os professores fizeram uso de aparatos tecnológicos (TV e DVD player) em consonância com as determinações do plano de aula, que contém a descrição das técnicas a serem adotadas pelo professor. 
Ficou muito evidente que o emprego da tecnologia nas aulas de LI estava condicionado às prescrições do plano de aula.

Além dessa crença comum aos quatro professores, podemos depreender outras duas crenças a partir das ações do professor Murilo, que inclusive coincidem com duas das três crenças desse professor levantadas por nós a partir de suas manifestações verbais. São elas:

- As novas tecnologias se constituem instrumentos de auxílio ao ensino, ao fornecerem subsídios audiovisuais utilizados pelo professor em sala de aula;

- As novas tecnologias viabilizam o acesso à informação de qualidade.

Os demais professores, ainda que manifestem verbalmente outras crenças levantadas por intermédio dos questionários, não nos parecem explicitar essas ou outras crenças em suas ações, salvo a crença comum já mencionada. Passemos, então, à comparação entre essas crenças manifestadas no dizer do professor e as crenças tácitas em seu fazer.

\section{A natureza da relação entre o dizer e o fazer do professor}

Em função da complexidade da relação que comumente se estabelece entre o dizer e o fazer do professor, conforme explicitamos no capítulo da fundamentação teórica, vale esclarecer aqui que optamos por identificar e discutir somente os tipos de relação predominantemente revelados pelo confronto entre o dizer e o fazer de cada um dos professores no contexto investigado. Salientamos, uma vez mais, que ao nos referirmos à comparação entre o dizer e o fazer do professor, não nos referimos ao confronto direto entre as crenças e as ações do professor, mas ao confronto entre a manifestação verbal de suas crenças e as crenças inferidas a partir de suas ações.

Ao traçarmos um paralelo entre tais crenças, conforme nos mostra o quadro 4 adiante, identificamos alguns pontos de consonância e alguns pontos de dissonância entre elas. Importante ressaltar que os últimos são mais numerosos que os primeiros, e os fatores que contribuem para essa discrepância serão discutidos posteriormente. 
Revista Eletrônica de Linguística (http://www.seer.ufu.br/index.php/dominiosdelinguagem) Volume 6, - $\mathrm{n}^{\circ} 2-2^{\circ}$ Semestre 2012 - ISSN 1980-5799

Quadro 4: Crenças manifestadas no dizer e no fazer do professor

\begin{tabular}{|c|c|c|}
\hline Professor & Crenças manifestadas no dizer do professor & Crenças manifestadas no fazer do professor \\
\hline \multirow{2}{*}{ João } & As novas tecnologias incrementam as aulas. & \multirow{2}{*}{$\begin{array}{l}\text { A utilização da tecnologia está condicionada às técnicas ditadas } \\
\text { pelo método de ensino adotado. }\end{array}$} \\
\hline & As novas tecnologias podem causar dependência. & \\
\hline \multirow{3}{*}{ Laura } & $\begin{array}{l}\text { As novas tecnologias influenciam positivamente a aprendizagem } \\
\text { de LI. }\end{array}$ & \multirow{3}{*}{$\begin{array}{l}\text { A utilização da tecnologia está condicionada às técnicas ditadas } \\
\text { pelo método de ensino adotado. }\end{array}$} \\
\hline & As novas tecnologias se restringem ao computador. & \\
\hline & $\begin{array}{l}\text { O uso das novas tecnologias no ensino de LI pode tornar o } \\
\text { processo um pouco mecânico. }\end{array}$ & \\
\hline \multirow{3}{*}{ Murilo } & As novas tecnologias atuam como um fator motivacional. & $\begin{array}{l}\text { A utilização da tecnologia está condicionada às técnicas ditadas } \\
\text { pelo método de ensino adotado. }\end{array}$ \\
\hline & $\begin{array}{l}\text { As novas tecnologias se constituem instrumentos de auxílio ao } \\
\text { ensino, ao fornecerem subsídios audiovisuais utilizados pelo } \\
\text { professor em sala de aula. }\end{array}$ & $\begin{array}{l}\text { As novas tecnologias se constituem instrumentos de auxílio ao } \\
\text { ensino, ao fornecerem subsídios audiovisuais utilizados pelo } \\
\text { professor em sala de aula. }\end{array}$ \\
\hline & $\begin{array}{l}\text { As novas tecnologias viabilizam o acesso à informação de } \\
\text { qualidade. }\end{array}$ & $\begin{array}{l}\text { As novas tecnologias viabilizam o acesso à informação de } \\
\text { qualidade. }\end{array}$ \\
\hline \multirow{3}{*}{ Paulo } & As novas tecnologias atuam como um fator motivacional. & \multirow{3}{*}{$\begin{array}{l}\text { A utilização da tecnologia está condicionada às técnicas ditadas } \\
\text { pelo método de ensino adotado. }\end{array}$} \\
\hline & $\begin{array}{l}\text { As novas tecnologias se constituem instrumentos de auxílio ao } \\
\text { ensino, ao fornecerem subsídios audiovisuais utilizados pelo } \\
\text { professor em sala de aula. }\end{array}$ & \\
\hline & As novas tecnologias podem causar dependência. & \\
\hline
\end{tabular}

Por intermédio do confronto entre essas crenças, depreendemos dois tipos de relação, a saber: uma relação de natureza dissonante, como pôde ser observado no caso dos professores João, Laura e Paulo, e uma relação de consonância, no caso do professor Murilo.

Tomemos inicialmente o caso do professor João. Apesar de ter a crença de que as novas tecnologias incrementam as aulas de LI, tornando-as mais ricas, ele não parece utilizá-las em suas aulas com esse propósito, se restringindo a adotá-las conforme o especificado no plano de aúla, ou seja, para fins de associação entre som e imagem, repetição, compreensão auditiva, de acordo com as técnicas ditadas pelo método de ensino adotado.

Fenômeno semelhante pode ser observado em relação ao professor Paulo, cuja utilização das novas tecnologias nas aulas de LI se restringe ainda mais às orientações prescritas pelo plano de aula utilizado por ele. Apesar de considerar as novas tecnologias um fator de motivação ao aluno e de visualizá-las como instrumentos de auxílio ao ensino por propiciarem subsídios audiovisuais adicionais, sua prática se restringe aos recursos exigidos pela instituição, limitando-se a utilizar a tecnologia como um ferramental para a aplicação das técnicas estabelecidas pelo método.

No caso da professora Laura, a dissonância entre as crenças manifestadas no seu dizer e as crenças manifestadas no seu fazer é igualmente observada. A professora 
afirma acreditar na indispensável contribuição da tecnologia para a aprendizagem de LI, o que nos levou a inferir sua crença sobre a influência positiva das novas tecnologias para a aprendizagem de LI (quadro 4). Portanto, esperava-se que a utilização das mesmas nas aulas de Laura não se restringisse a somente o prescrito pelo plano de aula.

Outra crença manifestada no dizer de Laura diz respeito à possibilidade do uso das novas tecnologias no ensino de LI tornar o processo um pouco mecânico. Essa crença está relacionada à preocupação da professora com o aspecto afetivo do ensino, conforme observamos no seguinte excerto:

[1] Laura: "Qualquer tecnologia no final das contas se torna repetitiva, então acho que por ela só não basta, por isso que ela só não basta.[...] Ela precisa de algo que traga, não sei, o emocional, assim, sabe, um carinho que a gente tem pelos alunos, assim, uma troca."

A sua prática em geral explicita uma preocupação em manter um relacionamento de proximidade com seus alunos, como por exemplo, ao fazer uso de apelidos, ao demonstrar estar ciente de questões pessoais deles e de sempre se posicionar próxima fisicamente de seus alunos durante as aulas. Acreditamos, portanto, que o fato de a professora restringir o uso da tecnologia para o meramente prescrito pelo método de ensino adotado pela escola possa ser justificado pelo temor demonstrado por ela que a tecnologia possa mecanizar esse processo.

Por sua vez, a relação entre o dizer e o fazer do professor Murilo no que tange à utilização das novas tecnologias no ensino e aprendizagem de LI apresenta um caráter consonante, isto é, as crenças manifestadas no que o professor realiza em suas aulas vem ao encontro do que ele afirma acreditar.

Em primeiro lugar, fica muito evidente a consonância entre suas crenças, posto que a todo momento durante suas aulas o professor faz uso da tecnologia para auxiliá-lo com subsídios audiovisuais e para o acesso a informações diversas, conforme as crenças manifestadas em seu dizer.

Por outro lado, a ostensiva utilização da tecnologia por Murilo em suas aulas é coerente com a sua crença de que as novas tecnologias atuam como um fator motivacional. Ainda que essa questão motivacional não seja uma crença inferida por nós no fazer do professor por não haver como afirmar que o que o leva a agir de tal 
maneira seja essa crença, a nosso ver, é esperado que um professor utilize em suas aulas algo que acredite motivar seus alunos.

\section{Fatores que se articulam na relação entre o dizer e o fazer do professor}

Com vistas a nos orientarmos a respeito das classes de fatores que afetam as crenças de professores, nos baseamos no trabalho de Borg (1999), e os nossos resultados apontaram para fatores inscritos nas três classes destacadas pelo autor: fatores contextuais, experienciais e cognitivos.

Ademais, identificamos uma quarta ordem, que se trata de fatores afetivos, que não foi contemplada no contexto de investigação de Borg (1999), mas que foi revelada pela análise dos nossos dados.

Esses fatores foram inferidos a partir da análise dos questionários e das entrevistas dos quatro professores, nos quais buscamos pistas que nos indicassem elementos subjacentes às crenças manifestadas tanto no dizer quanto no fazer desses professores. Tais fatores estão representados no diagrama 1, a seguir:

Diagrama 1: Fatores que influenciam a relação entre o dizer e o fazer do professor

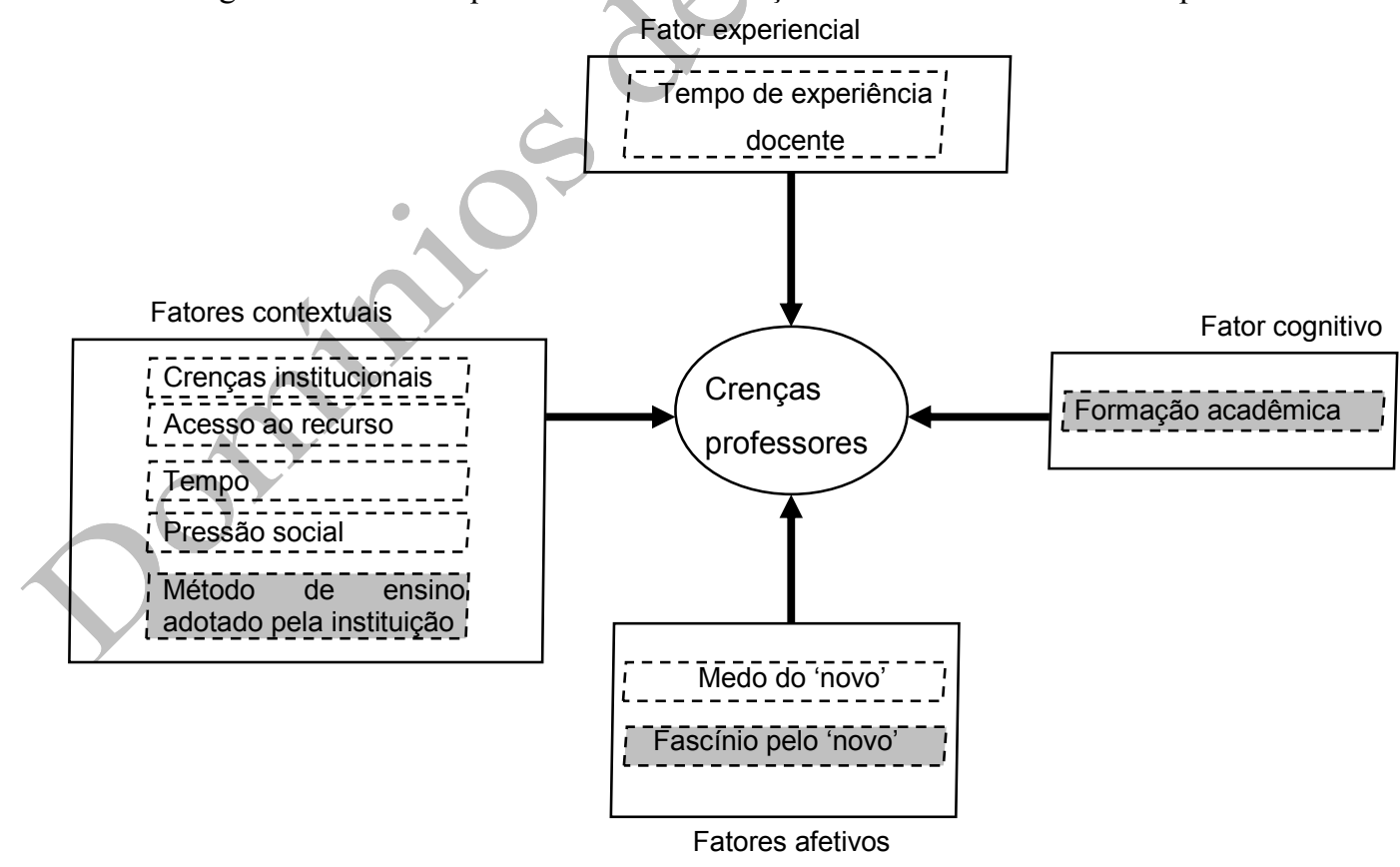

Podemos observar que os fatores contextuais se constituem os fatores de influência preponderante na relação entre o dizer e o fazer do professor na instituição pesquisada. Identificamos seis fatores de ordem contextual contra dois de ordem afetiva, 
e apenas um de cada uma das ordens experiencial e cognitiva. Ou seja, a influência do contexto na formação das crenças do professor, destacada em trabalhos como os de Damião (1994), Richardson (1996), Perina (2003), Pereira (2005) e Barcelos (2006), dentre outros, é corroborada pelos resultados obtidos a partir de nossa análise dos dados. Os resultados encontrados assinalam a relevância do contexto de trabalho no qual o professor se inscreve para a formação e manifestação de suas crenças.

Além disso, os fatores que fomentam a dissonância são predominantes, posto que foram identificados sete fatores com essa característica em oposição a apenas três que fomentam a consonância entre o dizer e o fazer do professor, sendo os últimos representados no diagrama pelos quadrinhos coloridos. Considerando que identificamos uma relação de dissonância entre o dizer e o fazer de três professores, e uma relação de consonância apenas no caso de um professor, a predominância de fatores que fomentam a dissonância era um resultado esperado.

Os dados demonstram que as crenças institucionais (quadro 1) se configuram um fator contextual de suma importância. A patente influência das mesmas na formação das crenças do professor apontam para o poder exercido pelo discurso coletivo na instituição investigada.

Outro fator contextual que parece exercer uma grande influência na relação entre o dizer e o fazer do professor é o acesso ao recurso. Os professores alegam que as salas de aula não dispõem mais de computadores, como no passado, e atribuem a isso o fato de não utilizarem as novas tecnologias como gostariam:

[2] Murilo: "Não tenho o notebook na sala todos os dias. Aí eu teria que trazer, E tem dias que eu não consigo trazer."

Temos ainda um terceiro fator contextual, que é a questão tempo. Os quatro professores justificam utilizar a tecnologia menos do que gostariam também com base no fator tempo, conforme afirma Laura:

[3] Laura: "Eu acho que é tempo mesmo, [...] falta de organizar mesmo o tempo, o cronograma." 
Outro fator contextual que, a nosso ver, contribui para o estabelecimento dessa relação entre o dizer e o fazer do professor é a pressão social imposta sobre este. Apesar de esse fator não ter ficado muito evidente na análise dos dados, posto que somente a professora Laura explicita essa questão, acreditamos na influência dele com base também em nossa experiência e observação.

Identificamos esse sentimento no seguinte excerto da entrevista com a professora Laura:

[4] Laura: "Eu falei, gente, não, não é possível, né? Eu tenho que entrar, né? Eu não vou ficar pra trás."

Esse mito da necessidade da tecnologia acaba por suscitar um sentimento de urgência, que é externalizado no dizer da professora em elementos como 'tenho' e 'não vou ficar pra trás'. Mas por uma série de outros fatores, essa necessidade aparente pode não chegar a ser efetivada em sua prática, gerando assim, a discrepância entre o dizer e o fazer da professora.

Abordamos, finalmente, o único fator contextual que, a nosso ver, fomenta a consonância entre o dizer e o fazer do professor. Os dados indicam que a principal motivação do professor para a utilização das novas tecnologias (notadamente da TV e do DVD) no ensino de LI reside no método de ensino adotado pela instituição, por intermédio das instruções prescritas no material didático utilizado pelos professores. Vejamos:

[5] João: "É uma característica imprescindível, sem a televisão e o DVD não tem jeito, porque a metodologia toda gira em torno do DVD e da televisão."

[6] Murilo: "Pela metodologia da escola. Por causa da metodologia, eu tenho que usar o DVD, televisão."

No que concerne à influência de experiências educacionais ou profissionais nas crenças do professor, os dados analisados revelam apenas um elemento que classificamos como um fator experiencial influente, que consiste no tempo de experiência docente do professor. 
Os excertos a seguir, extraídos da entrevista com a professora Laura, a professora mais experiente dentre os quatro participantes, denotam essa questão:

[7] Laura: "Olha, eu tenho 12 anos de metodologia [...] Eu vou te ser muito sincera, eu não sei se eu conseguiria sair da metodologia. Eu não sei se isso é negativo ou não, mas eu acho assim, que eu já me adaptei à metodologia."

No caso da professora Laura, o tempo de experiência docente parece ter um papel fundamental em suas escolhas pedagógicas.

No que concerne a fatores relacionados às concepções e percepções dos professores quanto ao papel das novas tecnologias no ensino e aprendizagem de LI, identificamos apenas um elemento que classificamos como um fator cognitivo influente, que consiste na formação acadêmica do professor.

Essa questão está relacionada ao professor Murilo, que se configura o único professor dentre os quatro participantes cuja formação não se inscreve dentro das Ciências Humanas, posto que quando da nossa coleta de dados Murilo acabara de se formar em Ciência da Computação.

Durante a entrevista semi-estruturada, solicitamos ao professor que refletisse a respeito das razões que o levavam a utilizar as novas tecnologias mais que os outros professores participantes. Diante de tal solicitação, o professor avaliou:

[8] Murilo: “Acho que é minha formação. Porque eu acho que as pessoas não utilizam não é porque elas não queiram, porque todos querem. [... Elas não têm assim, preparo, pra poder usar tudo, e pra saber onde procura. Porque a gente precisa saber onde que acha."

Ao investigarmos os fatores que influenciam as crenças do professor, nos deparamos ainda com questões relacionadas às emoções do professor. Esses fatores, aos quais nos referimos como fatores afetivos, não se enquadram diretamente em nenhuma das classes de fatores propostas por Borg (1999). Contudo, é inegável que se relacionem com o aspecto cognitivo da questão, mesmo que indiretamente, uma vez que o emocional tem o potencial para desencadear ou para reprimir o cognitivo. 
Os fatores afetivos de influência preponderante nas crenças do professor identificados por nós abrangem questões concernentes aos temores e desejos do professor.

O primeiro fator afetivo observado é o medo do 'novo'. Em um primeiro momento, as crenças manifestadas no dizer do professor parecem explicitar o desejo de uma utilização mais ostensiva das novas tecnologias, ou seja, o desejo de inovação. Contudo, os dados sugerem que, ao se deparar com a prática, surge o receio de se investir no desconhecido.

Esse temor é identificado sobretudo no dizer da professora Laura, que argumenta preferir não arriscar modificar uma situação na qual ela se sente confortável:

[9] Laura: "Eu acho que eu fico mais na minha experiência do que no 'novo'. Já tô naquilo ali, sei que aquilo ali funciona e eu vou seguindo aquilo, entendeu?"

Acreditamos que essa classe de fatores afetivos identificada em nosso trabalho possa ser mais explorada em pesquisas futuras para que se investigue de forma mais aprofundada a influência de fatores afetivos nas crenças de professores não somente no que tange à utilização de novas tecnologias, mas em múltiplos aspectos dos processos de ensino e aprendizagem de LI.

Estamos cientes de que este se configura apenas o nosso olhar sobre os dados, e certamente, diferentes naturezas de relação e outros fatores seriam identificados sob diferentes perspectivas. Acreditamos, contudo, que essa potencialidade se constitua precisamente a grande riqueza da pesquisa qualitativa de cunho interpretativista, em cuja natureza nosso trabalho se inscreve.

\section{Considerações finais}

Acreditamos que os resultados alcançados em nosso trabalho tragam relevantes implicações para a área de ensino e aprendizagem de línguas, pois apontam para algumas contradições que revelam a necessidade de se abordar os processos de ensino e aprendizagem de LI a partir de um ângulo mais amplo, que leve em consideração fatores diversos como o contexto de atuação do professor, a sua história e até mesmo suas emoções. 
Interpretamos as incongruências observadas entre o dizer e o fazer do professor com respeito às novas tecnologias como um alerta aos agentes educacionais, pois, por mais que seja importante se investir em tecnologia na atualidade, notadamente no universo educacional, de nada adianta modernizar o equipamento sem modernizar as práticas subjacentes ao seu emprego. E para modernizar tais práticas, é preciso focar o professor, ouvir o que ele tem a dizer, e acima de tudo, investir no professor.

É preciso deixar de buscar soluções externas para as questões educacionais e passar a encarar o processo de dentro pra fora, a começar pelo professor, posto que "nenhuma tecnologia é tão perfeita que possa prescindir do organizador da atividade didática." (GADOTTI, 1994 apud SAMPAIO; LEITE, 1999).

$\mathrm{O}$ foco de nossa investigação incidiu sobre o professor, pela precípua importância que atribuímos ao seu papel no processo educacional. Apesar de termos nos valido da perspectiva da coordenação pedagógica da escola, o nosso foco foi, indiscutivelmente, o professor.

Contudo, temos consciência de que esse processo é constituído por outros agentes não menos importantes e que, a nosso ver, merecem ter suas percepções abordadas no que diz respeito às novas tecnologias e o ensino e aprendizagem de LI. Assim, apontamos também para a necessidade de pesquisas futuras que abordem a questão das novas tecnologias a partir das perspectivas de outros agentes, como o diretor e o aluno. Por outro lado, nos questionamos que resultados seriam alcançados caso a pesquisa fosse conduzida em outros contextos educacionais, como a escola regular pública e privada, ou um curso de Letras.

Além da discutida dissonância entre as crenças do professor manifestadas em seu dizer e aquelas manifestadas em seu fazer, os resultados alcançados sinalizam ainda para outros pontos de contradição. Os dados nos mostram, por exemplo, que ora o professor visualiza as novas tecnologias enquanto qualquer aparato tecnológico à sua disposição, ora se refere a elas como se tratando somente do computador. Ora diz acreditar não poder ficar pra trás no que diz respeito à utilização da tecnologia na sala de aula de LI, ora afirma se sentir satisfeito com a sua prática estabelecida. As discrepâncias não são reveladas somente no confronto entre o dizer e o fazer do professor, mas aparentemente, em todos os aspectos relacionados às suas crenças. 
Além do rol de fatores levantados, essas divergências podem ser atribuídas também à própria natureza das crenças, que segundo Barcelos (2006), são dinâmicas, paradoxais e contraditórias, o que nos suscita o seguinte questionamento: como almejar a harmonia entre as crenças manifestadas no dizer do professor e as crenças manifestadas em seu fazer, se estas são em si inerentemente contraditórias? E mais além, por que buscar a harmonia? Por que almejar a consonância entre o que se pensa, o que se diz, e o que se faz?

A nosso ver, quando Mahatma Ghandi nos sugeriu sempre visar a completa harmonia entre pensamento, palavra e ação, seu objetivo era preconizar uma coerência de comportamento oriunda do desenvolvimento do autoconhecimento do índivíduo.

Vários são os ângulos a partir dos quais nossos dados podem ser analisados, e a todo momento eles parecem nos mostrar algo novo. Contudo, dentro do recorte no qual nos propusemos a trabalhar, encerramos aqui o nosso trabalho, sem, contudo, encerrarmos as nossas reflexões, pois "o conhecimento nunca se esgota, devendo estar aberto a reformulações", e "assim como a vida, se faz e se produz dia a dia" (SAMPAIO; LEITE, 1999, p.52).

\section{Referências}

ALLWRIGHT, D.; BAILEY, K.M. Focus on the language classroom: an introduction to classroom research for language teachers. Cambridge: Cambridge University Press, 1991. $160 \mathrm{p}$.

ALMEIDA, G. As. Novo milênio novo de novo. Disponível em: $<$ http://www.mundodosfilosofos.com.br/guilherme15.htm>. Acesso em: 28 abr. 2007

ALMEIDA FILHO, J. C. P. Análise de abordagem como procedimento fundador de auto-conhecimento e mudança para o professor de língua estrangeira. In: ALMEIDA FILHO, José Carlos Paes (Org.). O professor de língua estrangeira em formação. 2. ed. Campinas, SP: Pontes, 2005a. p. 11-27.

ANTHONY, E. Approach, method and technique. In: SMOLINSKI, F. (Ed.). Landmarks of American language \& linguistics. Washington: United States Information Agency, 1985. p. 199-202.

BARCELOS, A. M. F.. Understanding teachers' and students' language learning beliefs in experience: a Deweyan approach. 2000. $357 \mathrm{f}$. Tese (Doutorado em Ensino de Inglês como Segunda Língua) - The University of Alabama, Tuscaloosa, AL, USA, 2000 . 
BARCELOS, A. M. F.. Metodologia de pesquisa das crenças sobre aprendizagem de línguas: estado da arte. Revista Brasileira de Linguística Aplicada, Belo Horizonte, v. 1, n. 1, p. 71-92, 2001.

BARCELOS, A. M. F.. Crenças sobre aprendizagem de línguas, Lingüística Aplicada e ensino de línguas. Linguagem \& Ensino, Pelotas, v. 7, n. 1, p. 123-156, jan./jul. 2004.

BARCELOS, A. M. F.; BATISTA, F. de S.; ANDRADE, J. C.. Ser professor de inglês: crenças, expectativas e dificuldades dos alunos de Letras. In: VIEIRA ABRAHÃO, M. H. (Org.). Prática de ensino de língua estrangeira: experiências e reflexões. Campinas: Pontes, 2004. p. 11-29.

BARCELOS, A. M. F.. Cognição de professores e alunos: tendências recentes na pesquisa de crenças sobre ensino e aprendizagem de línguas. In: BARCELOS, A. M. F.; VIEIRA ABRAHÃO, M. H. (Org.). Crenças e ensino de línguas: foco no professor, no aluno e na formação de professores. Campinas: Pontes, 2006. p. 15-42.

BARCELOS, A. M. F.. Crenças sobre ensino e aprendizagem de línguas: reflexões de uma década de pesquisa no Brasil. In: ALVAREZ, M. L. O.; SILVA, K. A. (Org.). Lingüística Aplicada: múltiplos olhares. Campinas: Pontes, 2007. p. 27-69.

BASSO, E. A. Quando a crença faz a diferença. In: BARCELOS, A. M. F.; VIEIRA ABRAHÃO, M. H. (Org.). Crenças e ensino de línguas: foco no professor, no aluno e na formação de professores. Campinas: Pontes, 2006. p. 65-85.

BORG, S.. The use of grammatical terminology in the Second Language Classroom: a Qualitative Study of Teachers' Practices and Cognitions. Applied Linguistics, v. 20, n. 1, p. 95-126, 1999.

BROWN, H. D.. Teaching by principles: an interactive approach to language pedagogy. Englewood Cliffs, New Jersey: Prentice Hall Regents, 1994. 480 p.

BUZATO, M. E. K. Sobre a Necessidade de Letramento Eletrônico na Formação de Professores: O Caso Teresa. In: LOPES, R. E. V. et al. (Org.). Lingüística e Ensino: Novas Tecnologias. Blumenau: Nova Letra, 2001. p. 229-267.

CAVAlCANTI, M. C. Reflexões sobre a Prática como Fonte de Temas para Projetos de Pesquisa para a Formação de Professores de LE. In: ALMEIDA FILHO, J. C. P. (Org.). O Professor de Língua Estrangeira em Formação. Campinas: Pontes, 1999, p. $179-184$.

CORRÊA, J.. Novas tecnologias da informação e da comunicação; novas estratégias de ensino/aprendizagem. In: COSCARELLI, C. V. (Org.). Novas tecnologias, novos textos, novas formas de pensar. 2. ed. Belo Horizonte: Autêntica, 2003. p. 43-50.

DAMIÃO, S. M.. Crenças de professores de inglês em escolas de idiomas: um estudo comparativo. 1994. 116 f. Dissertação (Mestrado em Lingüística Aplicada ao Ensino de Línguas) - Pontifícia Universidade Católica de São Paulo, São Paulo, 1994. 
DUFVA, H.. Beliefs in dialogue: a bakhtinian view. In: KALAJA, P.; BARCELOS, A. M. F. (Ed.). Beliefs about SLA: new research approaches. 1. ed. Nova York: Springer, 2006. p. 131-152.

FREIRE, P. Pedagogia da autonomia: saberes necessários à prática educativa. 28. ed. São Paulo: Paz e Terra, 2003. 148 p. (Coleção Leitura).

GIMENEZ, T. N. Learners becoming teachers: an exploratory study of beliefs held by prospective and practising EFL teachers in Brazil. 1994. 343 f. Tese (Doutorado) Lancaster University, Lancaster, 1994.

HOUAISS, A.; Dicionário Houaiss da Língua Portuguesa. 2001. Disponível em $<$ http://houaiss.uol.com.br> Acesso em: 03 maio 2007.

LEFFA, V. J. O ensino de línguas estrangeiras nas comunidades virtuais. In: SEMINÁRIO DE LÍNGUAS ESTRANGEIRAS, 4., 2001, Goiânia. Anais... Goiânia: Gráfica e Editora Vieira, 2002. p. 95-108.

MALATÉR, L. S. de O.. A teacher's beliefs on foreign language teaching and learning: a classroom study. 1998. 143 f. Dissertação (Mestrado em Letras) Universidade Federal de Santa Catarina, Florianópolis, 1998.

PEREIRA, K. B.. A interação da abordagem de ensinar de um professor de inglês de escola pública com o contexto em sala de aula. 2005. 191 p. Dissertação (Mestrado em Estudos Linguísticos) - Universidade Estadual Paulista, São José do Rio Preto, 2005.

PERINA, A. A.. As crenças dos professores de inglês em relação ao computador: coletando subsídios. 2003. 92 f. Dissertação (Mestrado em Lingüística Aplicada e Estudos da Linguagem) - Pontifícia Universidade Católica de São Paulo, São Paulo, 2003.

RICHARDSON, V. The role of attitudes and beliefs in learning to teach. In: SIKULA, J.. Handbook of research on teacher education. 2. ed. New York: Macmillan, 1996, p. 102-119.

SALABERRY, M. R. The use of technology for second language learning and teaching: a retrospective. The Modern Language Journal, v. 85, n. 1, p. 39-56, mar. 2001.

SAMPAIO, M. N.; LEITE, L. S. Alfabetização tecnológica do professor. Petrópolis, RJ: Vozes, 1999. 111 p.

SILVA, K. A. Crenças sobre o ensino e aprendizagem de línguas na Lingüística Aplicada: um panorama histórico dos estudos realizados no contexto brasileiro. Revista Anual de Educação, v. 9, n. 9, p. 48-62, 2006. Disponível em: $<$ www.unianhanguera.edu.br $>$ Acesso em: 25 mar. 2007. 
SILVA, K. A.; ROCHA, C. H.; SANDEI, M. de L. R. A importância do estudo das crenças na formação de professores de línguas. Contexturas, APLIESP, v. 8, n. 8, p. 19-40, 2005.

SILVEIRA, M. I. M.. Línguas estrangeiras: uma visão histórica das abordagens, métodos e técnicas de ensino. Maceió: Edições Catavento, 1999. 103 p.

VECHETINI, L. R. Crenças sobre o ensino de vocabulário em língua estrangeira (inglês) para alunos iniciantes. 2005. 160 f. Dissertação (Mestrado em Lingüística Aplicada) - Instituto de Estudos da Linguagem, UNICAMP, Campinas, 2005.

VIEIRA ABRAHÃO, M. H.. Metodologia na investigação das crenças. In: BARCElOS, A. M. F.; VIEIRA ABRAHÃ̃, M. H. (Org.). Crenças e ensino de línguas - foco no professor, no aluno e na formação de professores. Campinas, SP: Pontes, 2006. p. 15-42.

WARSCHAUER, M. Computer-assisted language learning: an introduction. In: FOTOS, S. (Ed.). Multimedia language teaching. Tokyo: Logos International, 1996. p. 3-20.

Artigo recebido em: 29.09.2012

Artigo aprovado em: 17.12.2012 